\title{
COMO O ESTÍMULO AO EMPREENDEDORISMO É PERCEBIDO OU RECEBIDO PELOS UNIVERSITÁRIOS BRASILEIROS
}

Ana Beatriz Salles ${ }^{1}$

${ }^{1}$ Universidade Federal do Rio de Janeiro/Instituto de Economia/Programa de Pós-graduação em Políticas Públicas, Estratégias e Desenvolvimento 


\section{COMO O ESTÍMULO AO EMPREENDEDORISMO É PERCEBIDO OU RECEBIDO PELOS UNIVERSITÁRIOS BRASILEIROS}

\section{Resumo}

O fracasso das políticas ortodoxas de apoio ao empreendedorismo, focadas somente nas capacidades individuais e na intervenção estatal só nas falhas de mercado, levou os formuladores de política de países em desenvolvimento a prestar mais atenção ao contexto local a partir de meados dos anos 1990. No entanto, para Pessali (2011), uma fonte da ineficiência das políticas pode estar no processo de sua formulação, ao não levar em consideração, além do contexto, o que os atores envolvidos pensam.

Com o intuito de contribuir com as políticas públicas de apoio ao empreendedorismo, o trabalho a seguir apresenta os resultados do projeto de pós-doutorado que buscava evidenciar a visão e o conhecimento que os jovens universitários têm a respeito do ambiente institucional brasileiro, sua visão sobre a importância do ensino do empreendedorismo e o papel que as famílias, as escolas e as universidades exercem no esclarecimento destas questões.

Palavras-chave: empreendedorismo. instituições. políticas públicas.

\section{$1 \quad$ Introdução}

Segundo Wennekers e Thurik (1999), na década de 90, muitos economistas e políticos intuíram que o estímulo ao empreendedorismo teria um impacto positivo sobre o crescimento do PIB e do emprego.

Seguindo essa tendência mundial iniciada na década de 90, o movimento em busca de apoio efetivo ao empreendedorismo era ainda bastante recente no Brasil no início do Século XXI (Salles, 2008). Na ausência de políticas públicas, o movimento comportava diferentes objetivos de acordo com as inserções institucionais dos agentes envolvidos, a saber: promoção e apoio de novos negócios (Sebrae, Senac e Incubadoras de empresas); promoção à inovação (Finep, INPI, Incubadoras de Empresas e Parques tecnológicos); mudança de atitude frente à vida ou promoção de iniciativa para gerar mudanças (Educadores e Centros de empreendedorismo); promoção da inclusão social e geração de trabalho e renda (Incubadoras Sociais). Esse movimento era identificado por seus promotores como estímulo tardio ao verdadeiro capitalismo, pois se baseava não só na oportunidade para promoção do crescimento econômico mas também, e principalmente, na necessidade de promoção de uma cultura empreendedora que abrangesse o sistema institucional como um todo em prol de uma democratização da base produtiva.

As entrevistas realizadas por Salles (2008) com alguns desses gestores, educadores, consultores e empreendedores (startups e PMEs), permitem fazer as seguintes constatações sobre o contexto brasileiro (condições) à época: 
$>$ Movimento do empreendedorismo (denominado por um dos entrevistados como uma revolução invisível) era bottom-up e estava começando a entrar no radar dos Governos apenas como discurso

$>$ Concentração de incentivos, quando existentes, em inovação tecnológica (startups de base tecnológica e de grande potencial de crescimento) e estruturas físicas (incubadoras e parques)

$>$ O Estado brasileiro (em termos de ambiente econômico) era visto como pai ausente, "padrasto", ou pai super protetor conforme o segmento empresarial.

$>$ A resistência observada nas entidades de ensino fundamental e médio com relação à introdução da matéria empreendedorismo era atribuída à existência de uma mentalidade anticapitalista.

$>$ As escolas e universidades preparavam os jovens para serem empregados (coadjuvantes), e não empreendedores (protagonistas).

$>$ Carência de narrativas sobre exemplos positivos de empreendedorismo

$>$ Ambiente institucional disfuncional

$>\mathrm{O}$ famoso "jeitinho brasileiro" (na sua nuance negativa) haveria sido instituído como forma de contornar e conviver com um ambiente institucional nem sempre coerente e justo e, portanto, inóspito.

$>$ Analfabetismo institucional generalizado dos brasileiros sobre os sistemas institucionais: República, Capitalismo, Democracia

$>$ Carência de capital social e participação cidadã

$>$ Necessidade de construção da participação cidadã eliminando a clivagem simbólica entre social x econômico, elite x povo, público x privado

Em 2015, apesar de o movimento bottom-up do empreendedorismo ter se expandido e avançado, o mesmo ainda se defrontava com vários dos obstáculos (visíveis) e resistências (invisíveis) identificados acima (Salles, La Rovere e Santos, 2018).

Quais seriam, portanto, as chances de mudanças deste arcabouço institucional?

\section{Referencial Teórico}

\section{A importância do empreendedorismo para o crescimento econômico}

Segundo Wennekers e Thurik (1999), o empreendedorismo é sempre importante, pois ajuda a promover a competição e a inovação. Nas economias abertas modernas é mais importante para o crescimento econômico do que em qualquer outra época porque a revolução das tecnologias da informação e comunicação implicam a necessidade de mudanças estruturais que requerem uma realocação substancial de recursos. Sugerem, no entanto, que a relação da causalidade entre empreendedorismo e crescimento não poderia se resumir à criação de novas empresas.

Para eles, o conceito de empreendedorismo é mal definido, por ser, na melhor das hipóteses, multidimensional. Quando se referem a empreendedores, eles incluem os que abrem negócios inovadores, os intraempreendedores e os que simplesmente decidem abrir seu próprio negócio. 
Para Wennekers e Thurik (1999) empreendedorismo é a habilidade manifesta e a vontade de indivíduos sozinhos ou em times, dentro e fora das organizações existentes, de:

- perceber e criar novas oportunidades econômicas (novos produtos, novos métodos de produção, novos arranjos organizacionais, e novas combinações produto-mercado) e de

- introduzir suas ideias no mercado, em face à incerteza e outros obstáculos tomando decisões sobre locação, forma e uso de recursos e instituições.

Fica evidente que estes autores não reconhecem o empreendedorismo como uma ocupação, pois os empreendedores não são uma classe de pessoas bem definida. Segundo eles, a capacidade empreendedora de uma pessoa pode se manifestar apenas durante uma fase de sua carreira e/ou durante parte das suas atividades, porém ressaltam que a capacidade ou vontade de empreender dependem de condições culturais e institucionais que afetam o ambiente macroeconômico de diferentes maneiras.

Ao revisar a literatura sobre empreendedorismo em diversas épocas e diferentes países, eles concluem que o impacto das dimensões culturais na relação de causalidade entre empreendedorismo e crescimento econômico, apesar de significativa, não é direta, podendo ser diferente para cada nível de análise conforme Figura 1:

Figura 1: Estrutura final: vinculando empreendedorismo ao crescimento econômico

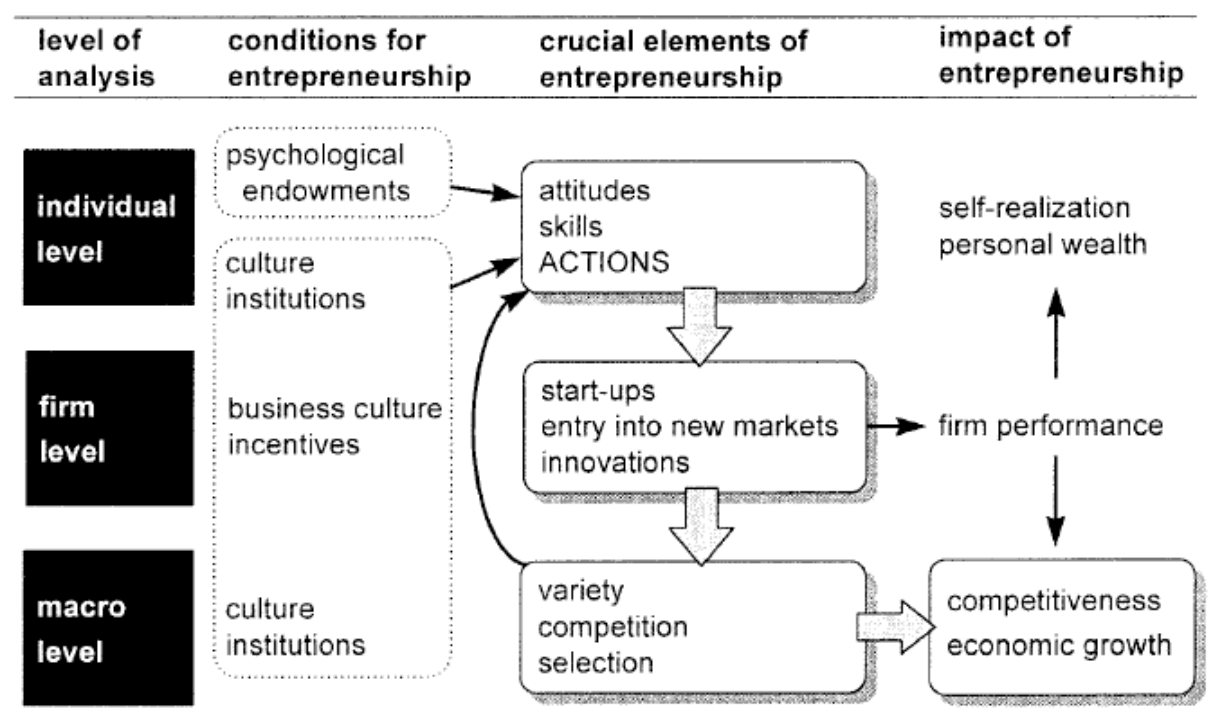

Fonte: Wennekers e Thurik (1999)

Para começar como empreendedor Van Praag (1996) afirma que são essenciais tanto a vontade como a oportunidade, onde oportunidade seria "a possibilidade de alguém empreender caso assim o queira", ou seja, depende de acesso a capital inicial, capacidade empreendedora e ambiente econômico favorável e onde a vontade depende das preferências individuais, das opções alternativas e do custo de oportunidade relativo. 
Segundo Baumol (1993) os arranjos institucionais e outros fenômenos sociais afetam tanto a quantidade quanto a alocação da capacidade empreendedora.

Levando em conta as constatações apresentadas na introdução sobre o nosso ambiente para o empreendedorismo, poderíamos dizer que há uma incompatibilidade entre desenvolvimento econômico e o ambiente cultural brasileiro?

\section{Como se formam os ambientes institucionais}

Segundo Douglas North (1990, p.3) as instituições formais e informais são "humanly devised constraints that shape human interaction" e que, portanto "they structure incentives in human exchange, whether political, social or economic", sendo "the underlying determinant of economic performance."

Sobre a possibilidade de mudanças , North (2005, p. viii-ix) afirma que as crenças que indivíduos, grupos ou sociedades sustentam e que determinam suas escolhas, são uma "consequence of learning through time", mas não só no transcurso de sua vida ou de sua geração, mas o aprendizado acumulado "passed on intergenerationally by the culture of a society" - as crenças, os mitos, as práticas e sistemas simbólicos que compõem a cultura de uma sociedade. A variação imensa na performance das diferentes sociedades deixam claro que o componente cultural é também central para a performance econômica e das políticas ao longo do tempo.

O processo educacional, portanto, deveria focar no que é aprendido ou compartilhado entre os membros de uma sociedade e no processo incremental pelo qual essas crenças e preferências foram construídas e/ou podem ser mudadas.

Corroborando com a visão de North, Jessé Souza (2006, p.19) ao explicar a Teoria de Ação Social afirma que "obedecer a uma regra social é antes de tudo uma prática 'aprendida pragmaticamente' e não 'um conhecimento dentro da cabeça das pessoas'". A prática social pode ser articulável, ou seja, ela pode explicitar razões e explicações para o seu 'ser deste modo e não de qualquer outro' quando desafiada a isto, mas na maior parte das vezes, esse pano de fundo inarticulado permanece implícito, comandando silenciosamente nossa atividade prática e abrangendo muito mais que a moldura das nossas representações conscientes."

Deirdre McCloskey (2008), também aponta nessa direção, ao afirmar que o fator que realmente impulsionou a revolução política e econômica realizada pelos países considerados desenvolvidos e democráticos atualmente foi o poder da retórica (poder de convencimento) que abriu espaço para as novas ideias e sistemas de organização social.

Salles (2008) sugere que o atraso brasileiro seria, em grande parte, provocado, não por uma incapacidade "congênita" do povo, mas sim pela falta de esclarecimento/convencimento geral sobre as regras do jogo capitalista (em termos econômicos), e republicano (em termos políticos) devido a falhas na institucionalização das mesmas. Essa carência permite a retroalimentação da incoerência e da ineficácia do ambiente institucional brasileiro na aplicação e reforço das mesmas e lhe cerceia o potencial empreendedor e a responsabilidade cidadã. Desta maneira, as mudanças só seriam possíveis se houvesse maior entendimento, transparência e debate sobre o ambiente institucional que nos cerca (regras formais e informais). Sendo assim, o grande desafio em termos de políticas públicas seria: a educação dos brasileiros para além do simples repasse de conhecimentos. 


\section{A inserção do empreendedorismo nas escolas e universidades}

Para Amorim (2018), se a missão da escola, além de preparar os estudantes para o mercado de trabalho, é formar cidadãos críticos e conscientes que possam contribuir como agentes de mudança na sociedade, deveríamos nos perguntar como o sistema atual de educação está lidando com a mesma.

Segundo Ramos e Roitman (2011), melhorar a qualidade da educação brasileira é um desafio urgente e necessário. A escola deve estimular e desenvolver a formação de cidadãos, oferecendo uma nova concepção pedagógica, que busque privilegiar e desenvolver o conhecimento integrado, priorizando a autoestima, o autocontrole, a criatividade, a autonomia, a crítica construtiva e principalmente a iniciativa empreendedora de cada educando.

Dolabela (2003), criador da Pedagogia Empreendedora, assim como, Veiga (2006), Dornelas (2014) e Lopes (2010), dentre outros autores, defendem a implementação do estímulo ao empreendedorismo nas escolas públicas e privadas no Brasil, pois veem na formação escolar, um meio significativo de desenvolver nas futuras gerações, conceitos básicos de cidadania, igualdade e desenvolvimento socioeconômico, viabilizando a construção de um mundo melhor para todos.

Segundo Lavieri (2010), apesar de a educação empreendedora ser um assunto em processo de valorização, a falta de uma cultura empreendedora e a pouca disposição em discuti-la ainda bloqueiam os principais efeitos positivos que dela podem advir.

A implantação da Educação Empreendedora nas escolas básicas, é recente e desafiadora e, segundo Amorim (2018), apesar de existirem iniciativas para promover e implantar a EE no país, poucas delas tem perspectiva de longo prazo que contribua para a formação inovadora e um desenvolvimento social consistente. Mesmo diante de tantas mudanças significativas no contexto geral, existem problemas recorrentes e não resolvidos, que impedem sua efetivação nas redes de ensino básico, nos forçando a viver numa realidade contraditória e crítica de nossa sociedade, tão ansiosa por mudanças.

Se Amorim apresenta um resumo do ambiente institucional das escolas básicas em 2018, o relatório sobre o EMPREENDEDORISMO NAS UNIVERSIDADES BRASILEIRAS (SEBRAE, 2016) nos dá um panorama do ensino superior em 2016. Resultado da quarta edição da pesquisa realizada pelo Sebrae e pela Endeavor Brasil com o objetivo de direcionar as estratégias das universidades e das lideranças que trabalham com o tema no Brasil, sejam professores, reitores ou formuladores de políticas públicas, a pesquisa contou com a participação de 2230 alunos e 680 professores pertencentes a mais de 70 instituições de ensino superior de todas as regiões do País trazendo à luz fatos que podem explicar as porcentagens apresentadas no Gráfico 1: 
Gráfico 1: Principal motivo para não ter interesse em empreender

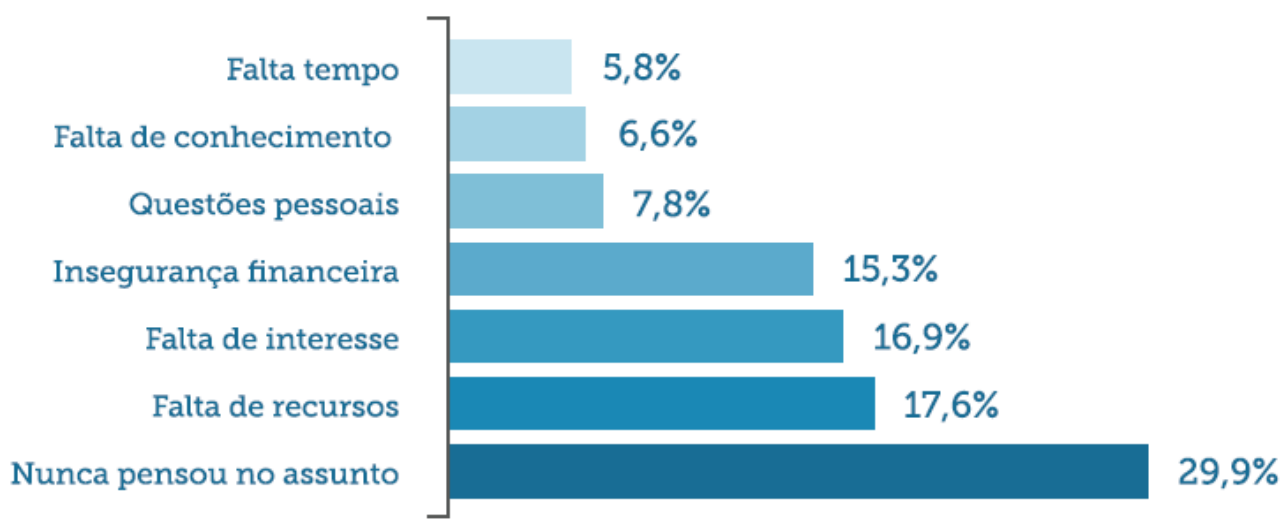

Fonte: SEBRAE (2016)

Entre as constatações trazidas pelo relatório destacam-se:

1) Poucos cursos universitários oferecem disciplinas de empreendedorismo, e quando oferecem, a maioria das disciplinas são oferecidas ou no começo ou ao final do curso, quando ainda é muito cedo ou já é muito tarde para promover mudanças.

2) Há diferenças regionais entre oferta e presença estudantil em disciplinas de empreendedorismo: As universidades do Centro-Oeste se destacam na oferta de disciplinas de empreendedorismo, enquanto quase metade das universidades do Nordeste não possuem nenhuma delas. A região Norte apresenta a menor proporção de alunos que cursam disciplinas de empreendedorismo, enquanto o Sudeste e o Sul possuem números próximos, de cerca de $30 \%$.

3) Atualmente, há uma relação direta entre um aluno cursar uma disciplina de empreendedorismo e o seu perfil empreendedor, pois o grupo que cursou disciplinas de empreendedorismo é o mesmo que já pretendia empreender nos próximos três anos.

4) Quem ainda não empreende tem percepção maior dos desafios, quando comparado a quem já tem ou conhece alguém que tem um negócio: essa percepção pode desmotivar empreendedores em potencial, e é possivelmente um dos motivos de parte deles nunca chegar a pensar em/ou realizar a vontade de abrir um negócio. Cursar disciplinas de empreendedorismo pode diminuir essa diferença de percepção

6) A universidade está desconectada do mercado, pois a institucionalização de atividades empreendedoras não é prioridade das universidades, gerando falta de interação com o ecossistema empreendedor local e pouca troca de apoio das universidades com o mercado.

7) A universidade não é agente central de apoio aos desafios dos seus alunos empreendedores.

E, o mais grave:

8) A universidade não é o principal fator de inspiração do aluno.

O relatório acima, portanto, nos permite afirmar que a situação nas universidades não difere em muito da situação das escolas de ensino básico.

Num contexto em que a crise de desemprego atual não pode ser atribuída somente a razões conjunturais, mas também, em grande parte, a mudanças estruturais na organização produtiva da sociedade, e em que o sistema de ensino parece ver com desconfiança o incentivo ao empreendedorismo, como fazer? 


\section{A percepção dos universitários sobre o ambiente institucional brasileiro atual}

Apesar de Amorim (2018) considerar que o que falta é "a formulação e/ou a permanência de políticas públicas já implementadas", a vontade política não se gera espontaneamente, dependendo do apoio ou da crítica de uma sociedade mais consciente de seus direitos e deveres, vigilante e participante, pois Olson (1982) alerta para o fato de que grupos de interesse (sindicatos, cartéis, corporativismo, etc) podem retardar a capacidade de uma sociedade de adotar novas tecnologias e realocar recursos em resposta às condições mutantes, o que acaba por reduzir a taxa de crescimento econômico de um país. Geralmente, quando isso ocorre, o dano para a sociedade é muito maior do que o ganho para o grupo de interesse.

Os eventos por que passou o Brasil nos últimos 10 anos (2008 - 2018), a saber:

- Manifestações de 2013 - Solicitando padrão FIFA para saúde e educação

- Manifestações espontâneas de 2015 contra as pedaladas fiscais e contra a corrupção

- Impeachment Presidente Dilma Roussef - 2016

- Operação Lava-jato - quebra de um padrão de impunidade

- O conservadorismo e o liberalismo adquirindo voz no debate político

- Eleições de 2018 - Polarização entre extremos (fatos ficam comprometidos por vieses ideológicos)

- O protagonismo das redes sociais e o flagelo das fake news

- Nova x Velha política - surgimento de novas lideranças e movimentos organizadores da sociedade civil

ensejaram nossa curiosidade a respeito da possível sinalização de mudanças na conscientização dos jovens brasileiros sobre os desafios futuros que o País lhes apresenta. Qual o conhecimento que os jovens têm do ambiente institucional que os cerca, assim como, qual a clareza que têm dos conceitos que devem ser base para as discussões políticas, e se veem a si mesmos como partícipes na construção de seu futuro coletivo.

A importância para a elaboração de políticas públicas de se levar em conta a percepção transmitida pela cultura aos atores envolvidos ilustrada na Figura 2 (La Rovere et al, 2018), fez com que procurássemos desenvolver uma ferramenta com o objetivo de se tentar explicitar a influência desse softpower sobre os nossos jovens. 
Figura 2: Segmentação para o desenho de políticas de apoio às empresas e ao empreendedorismo)

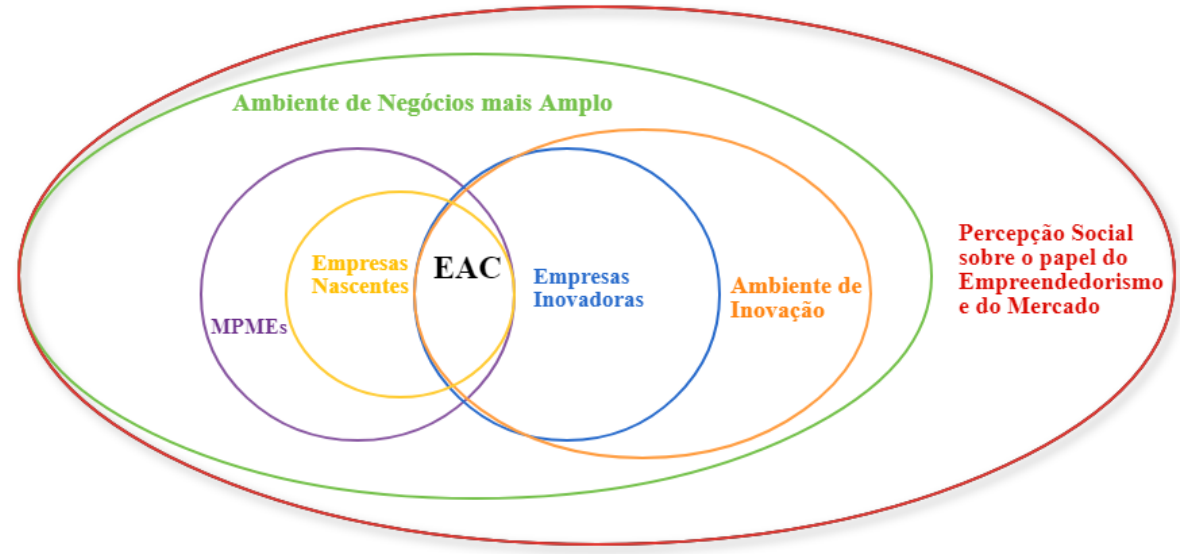

Legenda: EAC = Empresas de Alto Crescimento; MPMEs = Micro, Pequenas e Médias Empresas

Fonte: La Rovere, Salles e Santos (2018)

Levando em consideração a sugestão de Wennekers e Thurik (1999) de que o papel do ambiente cultural merece maior investigação devendo se distinguir sua influência nos níveis individual, da firma e do país sobre os seguintes atributos:

- mente aberta para outras culturas

- curiosidade, criatividade e experimentação

- perseverança

- valorização da riqueza e da poupança

- aceitação do risco e do fracasso

- competitividade

passamos a relatar alguns dos resultados obtidos com o projeto de pós-doutorado.

\section{Resultados da Pesquisa}

O questionário-teste inseriu perguntas de múltipla escolha, caixas de seleção e escala de avaliação, divididas em cinco blocos:

- Bloco I: Contexto pessoal e familiar

Renda familiar, formação e local de trabalho dos responsáveis, dados sobre escola e universidade, fontes de referência

- Bloco II: Atitudes e valores

Posicionamento seu ou de familiares frente a algumas questões

- Bloco III: Educação empreendedora

Cursos e estruturas oferecidos pelas escolas e universidade como preparação para o mercado e participação cidadã

- Bloco IV: Conhecimento do ambiente institucional

Esclarecimento sobre conceitos e papel das instituições 
- Bloco V: Opiniões

Nível de concordância com opiniões emitidas em 2008

A utilização da plataforma Google Forms permitiu que o link com o questionário: https://docs.google.com/forms/d/e/1FAIpQLScrcXf1YBmfB8wDGSg0Zd4hDMqZ0Uo1b53p -F4DTxcOOEkteA/viewform?usp=sf_link,

fosse enviado via email ou WhatsApp a universitários cursando graduação em todo o território nacional. No teste foram contatados informalmente, como multiplicadores, professores, conhecidos e amigos que tivessem contato com estudantes no nível de graduação em faculdades públicas ou privadas, na expectativa de atingir um universo de 200 estudantes.

A aplicação foi feita durante o segundo trimestre de 2019 e obteve uma taxa de retorno/expectativa de $21 \%$. As respostas permitem fazer algumas considerações sobre a adequação da ferramenta, assim como sobre a visão dos universitários e o apoio que estão recebendo para serem protagonistas de suas próprias vidas.

Obtivemos resposta de universitários do RJ (36), MG (5), RS (1) e ES (1), sendo 28 homens e 15 mulheres. Desse total, 48,6\% da área Sociais e Humanas, 32,6\% de Exatas e Tecnológicas, $14 \%$ de Saúde e Bem-estar e 4,7\% de Comunicação e Artes, representando uma diversidade interessante para a nossa análise. Dos respondentes, 62,8\% estudam atualmente em universidades públicas, tendo $65,1 \%$ cursado escolas privadas. Um dado que chama a atenção sobre a mobilidade dos estudantes no Brasil é que a grande maioria $(83,7 \%)$ estuda no mesmo estado em que cursaram a escola.

Nas perguntas sobre contexto pessoal e familiar destacamos os seguintes aspectos:

Em termos de renda familiar o resultado mostra a seguinte distribuição entre as classes econômicas das famílias desses estudantes: $46 \%$ com renda familiar acima de R \$ 9370,00, $20,9 \%$ com renda na faixa de $\mathrm{R} \$ 9370,00$ a $\mathrm{R} \$ 3748,00$ e $32,5 \%$ com renda familiar inferior a $\mathrm{R} \$ 3748,00$.

Chamou especialmente a atenção o fato de as mães apresentarem maior nível de formação que os pais em todos os níveis, exceto o médio (ver Gráfico 2)

\section{Gráfico 2: Nível de formação dos pais}

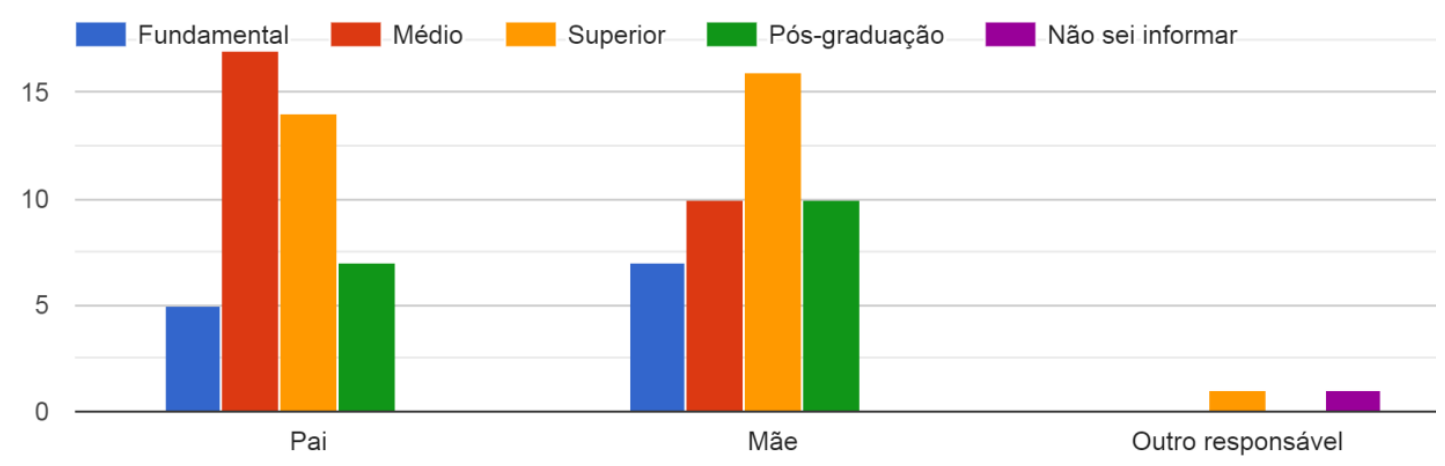

Fonte: Elaboração própria 
Ao serem perguntados sobre onde os responsáveis trabalhavam na maior parte do tempo que eles tinham lembrança, observamos uma concentração e quase o mesmo número de pais e mães ocupados com organizações públicas (16 pais e 11 mães) e com empresas próprias ou como autônomos (14 pais e 11 mães), seguidos pelos que trabalham em empresas privadas (11 pais e 10 mães) e poucos dedicados ao terceiro setor (1 pai e 3 mães).

No Bloco II, sobre Hábitos e Valores, ao serem perguntados sobre os assuntos que costumam ler, $62,8 \%$ dos universitários informaram ler não-ficção, sendo apontados como assuntos de maior interesse: análise do mundo atual $(55,2 \%)$, História $(41,4 \%)$ e Biografias (37,9\%). Além de não-ficção, 46,5\% também leem ficção. Chamou a atenção, no entanto, o fato de 23,3\% afirmarem não ter o hábito de leitura.

Para obter informações ou se inteirar de notícias, a internet se apresenta como o principal meio (95,3\%), seguida das redes sociais $(27,9 \%)$, noticiários de TV $(25,6 \%)$ e jornais e revistas $(23,3 \%)$, sendo o rádio mencionado por apenas $9,3 \%$.

Ao serem perguntados sobre experiência de trabalho, 53,5\% informaram que trabalham e estudam, 20,9\% que já trabalharam e 25,6\% que nunca trabalharam.

Em termos de participação cidadã: 69,8\% disseram participar normalmente das tarefas domésticas, enquanto $23,3 \%$ só o fazem quando solicitados; $65,1 \%$ já participaram de algum trabalho voluntário; $25,6 \%$ participam de alguma ação coletiva no condomínio/bairro/comunidade. Em termos de responsabilidade financeira, 37,2\% gastam mais do que ganham, enquanto $11,6 \%$ não fazem esse controle.

$\mathrm{Na}$ visão dos universitários entre as atitudes prejudiciais à civilização brasileira, o "achar que o país não tem jeito" concentrou as avaliações muito e extremamente prejudicial (95\%), seguidas de "achar que quem é pobre é obrigatoriamente menos capaz" (93\%), Racismo (88\%), Homofobia (86\%), Complexo de vira-lata (81\%), Misoginia e "achar que quem é rico é necessariamente corrupto" (ambos com 79\%).

Ao serem perguntados onde pretendem trabalhar quando se formarem, 25,6\% apontaram o setor público, 20,9\% em seu próprio negócio, 9,3\% como profissional autônomo, $16,3 \%$ em empresas privadas. Chama a atenção, a porcentagem de $14 \%$ que pretendem sair do país para trabalhar no exterior.

Entre as motivações mais importantes para essa escolha 83,7\% apontaram "oportunidade de crescimento"; 81,4\% "expectativa de realização pessoal"; 67,4\% "possibilidade de contribuir com a sociedade"; 60,4\% "salário oferecido"; 53,9\% "empresa ser reconhecida no mercado" e "garantia de estabilidade"; 48,8\% "expectativa de ganhos financeiros"; 46,5\% "poder influenciar o mundo que o cerca", 44,1\% "beneficios oferecidos" e, por último, somente 30,2\%, "desafio".

Apesar de 88,4\% declararem que gostariam de trabalhar em empresas inovadoras, e de 90,7\% considerarem que a responsabilidade pelo seu desenvolvimento profissional é sua, $51,2 \%$ consideram que a maior oportunidade de crescimento ou aprendizado profissional está nas empresas de grande porte e $38,5 \%$ em empresas de médio porte.

No bloco III sobre educação empreendedora, ao serem confrontados com o conceito de empreendedorismo como "pró-atividade, criatividade, capacidade de definir parâmetros e conseguir os meios para atingir os resultados", 88,4\% dos universitários disseram que o ensino do empreendedorismo seria relevante para qualquer atividade profissional, com apenas 9,4\% afirmando que só teria importância para quem quer abrir um negócio. 
Ao serem perguntados sobre qual seria a reação das famílias caso dissessem que gostariam de abrir seu próprio negócio, $46,5 \%$ responderam que a família incentivaria mas daria conselhos sobre como realizar o que pretende de forma realista; $23,3 \%$ lhe aconselhariam a fazer um concurso público, $14 \%$ desestimulariam dizendo que seria um horror, pois é dificil ser empresário no Brasil, e 7\% diriam que é melhor buscar um emprego com carteira assinada.

Sobre estímulo à participação nas escolas, $86 \%$ disseram que as mesmas promoviam eleições para representante de turma mas que só 48,8\% convidavam os alunos para participar ou sugerir soluções nos problemas do dia-a-dia escolar e apenas $9,3 \%$ ofereciam educação financeira.

Com relação ao apoio das mesmas na decisão profissional, $58,1 \%$ dos respondentes afirmam que tiveram apoio, a saber: palestras com diferentes profissionais (69\%) e testes vocacionais $(27,6 \%)$ e apoio psicopedagógico $(17.2 \%)$.

$69,8 \%$ dos respondentes declararam ter tido contato com o termo "empreendedorismo" na escola, enquanto nas universidades essa porcentagem cresce para 79,1\%.

Sobre se a universidade tem alguma estrutura que apoie a sua saída para o mercado, $53,5 \%$ afirmaram que sim, 27,9\% que não, e 18,6\% afirmaram não saber.

$\mathrm{Na}$ percepção dos respondentes sobre a capacidade das universidades estimularem o pensamento crítico e a iniciativa, $9,3 \%$ dizem que sua universidade estimula o simples repasse do conhecimento teórico, enquanto $41,9 \%$ afirmam que a sua estimula o desenvolvimento do pensamento crítico mas em nível teórico e, por fim, $14 \%$ consideram que sua universidade os estimula a extrair e expor suas próprias conclusões propiciando o debate entre pensamentos divergentes. Por outro lado, 23,3\% dizem que as universidades estimulam a prática/aplicação dos conhecimentos recebidos e $11,6 \%$ dizem que são estimulados a propor soluções e testalas.

No bloco IV, sobre o ambiente institucional brasileiro, $93 \%$ dos jovens acham que o mesmo é incoerente.

Ao serem perguntados sobre a que se deve o "atraso" brasileiro, 30,2\% responderam que se deve à incapacidade de políticos de resolver a desigualdade social, 20,9\% à falta de reforço e de respeito às regras já existentes, $16,3 \%$ responderam que se deve "à criação de regras contraditórias e inadequadas a um sistema capitalista", e 11,6\% à resistência em geral por falta de entendimento do que seja verdadeiramente um sistema capitalista.

As porcentagens a seguir mostram a percepção dos universitários sobre a presença de algumas condições no ambiente econômico brasileiro: direitos de propriedade garantidos $(25,6 \%)$; estabilidade monetária (25,6\%); respeito e fiscalização no cumprimento da legislação (7\%); transparencia legal e financeira (9\%); abertura de mercado $(32,6 \%)$; programa de governo claro (4,7\%); ambiente competitivo justo (2,3\%); infraestrutura adequada $(2,3 \%)$; mão de obra qualificada $(18,6 \%)$; capital humano $(60,5 \%)$ e capital social $(20,9 \%)$.

Sobre a possibilidade de mudança deste contexto $48,8 \%$ dos jovens acham que as mudanças devem começar a partir de si mesmos como indivíduos, 37,2\% por meio do esforço de organização da sociedade civil, e apenas, $14 \%$ a partir do poder público. 
Nos últimos cinco anos, os universitários declararam que seu interesse a respeito de alguns assuntos cresceu, a saber: Política (69,7\%), História brasileira e Participação na política $(58,1 \%)$.

Quando apresentados a atributos como democracia, livre mercado, propriedade privada, meritocracia, livre iniciativa, responsabilidade social e direitos humanos, os universitários associaram os cinco primeiros mais à visão liberal e os dois últimos, à visão socialista, refletindo o dilema e o reducionismo que se apresenta nos debates políticos que fazem dessas duas visões, soluções aparentemente excludentes, conforme Gráfico 3:

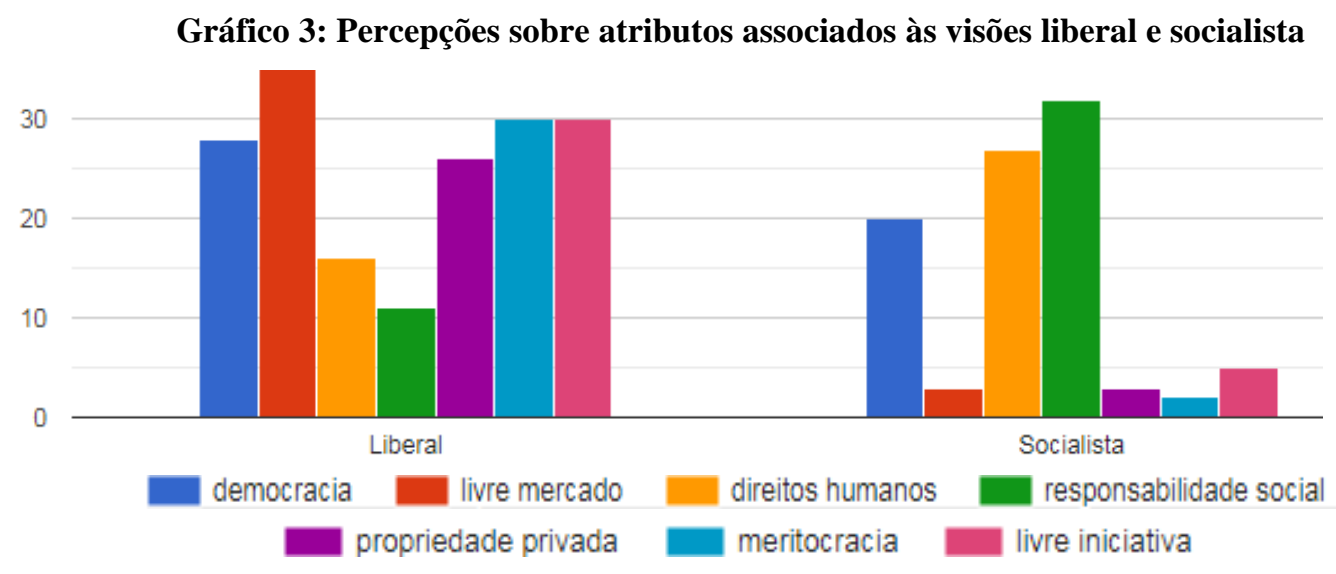

Fonte: Elaboração própria

Nas eleições de 2018, 72,1\% declararam que escolheram seus candidatos porque seus programas defendiam as causas em que acreditam, 11,6\% escolheram seus candidatos porque seu voto seria útil para derrotar outro candidato e $9,3 \%$ declararam que não votaram porque não acreditam em política, $2 \%$ porque era um nome conhecido e $1 \%$ porque alguém recomendou.

Após as eleições, 51,2\% dizem que acompanham as ações de seus candidatos no legislativo, 16,3\% dizem que gostariam de acompanhar mas não sabem como fazê-lo, e 27,9\% dizem que não acompanham.

No bloco V, com as opiniões proferidas em 2008 por alguns especialistas sobre o ambiente institucional, 69,7\% concordam em parte ou totalmente que "os impostos no Brasil servem para a manutenção de uma máquina que não produz resultados esperados como: educação, saúde, segurança nem infraestrutura", 58\% concordam que "o corporativismo das organizações públicas bloqueia as reformas estruturais necessárias ao País", e a mesma porcentagem concorda que "o setor público ao invés de resolver as dificuldades e entraves, cria novas estruturas para resolver os problemas que ele mesmo cria".

Sobre os hábitos e atitudes mais comuns entre os brasileiros: 55,8\% concordam que nossa "sociedade, apesar de nova, se posiciona como velha, estando capturada pelo passado sem estar preparada para batalhar o futuro"; $48,8 \%$ concordam que "tem muita gente infeliz no que faz, mas que não arrisca mudar por medo do novo"; e, 41,8\% concordam que "os brasileiros gostam de reclamar, mas não participam de ações coletivas". 
Sobre a educação que é oferecida nas escolas e universidades como estímulo à participação cidadã e ao empreendedorismo: $79 \%$ concordam que a "sociedade em geral desconhece o papel dos agentes governamentais em termos de suas atribuições, do que fazem, ou do que têm a ofertar", e 58\% consideram que "as faculdades brasileiras são boas, mas o mundo real está longe da sala de aula". Neste quesito, $13 \%$ dos jovens se sentiram incapazes de emitir opinião. Sobre se o "Brasil tem mais capacidade de gerar conhecimento, do que de transformar o conhecimento em riqueza", 44\% concordam, 37\% discordam e 16\% não sabem avaliar.

\section{Conclusão}

Apesar do projeto de pós-doutorado ter sido apenas o teste de uma ferramenta que ainda deve ser aperfeiçoada no seu conteudo e forma de aplicação, os resultados obtidos nos permitem fazer algumas considerações a respeito de como estamos nos níveis apontados por Wennekers e Thurik (1999).

No nível individual nos revelam, para aprofundamento da análise, os hábitos e valores e a influência familiar; no nível das firmas, aqui representadas pelas escolas e universidades, a percepção dos atores sobre a cultura da mesmas como inspiradoras e portadoras de futuro e, por fim, no nivel do País, a percepção dos atores sobre como o ambiente institucional e econômico abraça e incentiva o potencial empreendedor de sua população. Para exemplificar:

No nível individual: a influência e o peso da e na cultura do pensamento "o País não tem jeito", a falta de perspectiva e o desvio manifestos na busca e/ou pressão familirar por segurança em um emprego público ou em empresas de grande porte, a falta de preparo para o enfrentamento de um mundo que está em plena ruptura de paradigmas representada pela refração evidente ao desafio como motivação nas escolhas profissionais.

No nível das escolas e universidades (firmas): o conservadorismo, o simples repasse do conhecimento ou a crítica teórica, a falta de preparo prático e conceitual para o exercício da cidadania plena com respeito ao debate sobre o ambiente institucional que as cerca (democracias, repúblicas e sistemas econômicos), a falta de preparo e o distanciamento para compreender, se inserir e se preparar para modificar a realidade extramuros.

No nível do ambiente econômico como um todo: a percepção da falta de coerência e o descrédito nos resultados oferecidos e falta de capacidade de apoio e geração de oportunidades dos arranjos institucionais vigentes.

À falta de perspectivas impregnada nessas percepções, no entanto, também se contrapõe alguns sinais de mudança entrevistos em algumas das respostas: os jovens consideram que não se pode esperar que as mudanças necessárias venham por obra e graça só do poder público, existe um crescente interesse por assuntos referentes à participação política, um significativo número de jovens declara participar de assuntos ligados ao coletivo, alguns já veem como perspectiva a abertura de negócios próprios. Muitos confiam na existência de capital humano (na acepção de potencial), que está sendo restringido pela baixa qualificação. Por fim, ressalta-se a grande aceitação pela inserção da prática empreendedora nos diversos cursos universitários.

Para essas percepções poderem ser generalizadas nessecitaríamos de um universo mais amplo de aplicação, mas as respostas obtidas já atestam preliminarmente que temos maneiras 
de captar o que os atores sentem e pensam de forma a permitir uma reavaliação e mudança das práticas que geram ou reificam essas percepções, conforme Souza e North avaliam ser importante.

Se vamos deixar que esse sistema de crenças continue sendo repassado de geração em geração ou se a reavalição e mudança dessas práticas serão obtidas de forma top-down (do nível macro para o individual por meio de políticas públicas) como sugerem Amorim (2018) e o relatório Sebrae/Endeavor (2016) ou bottom-up (do nível individual para o macro por meio da conscientização e pressão da sociedade civil) como a observação de Olson (1982) indica ser algumas vezes necessário, é uma questão em aberto.

\section{Referências bibliográficas}

AMORIM, Djanine Almeida. A Pedagogia Empreendedora Na Educação Básica Brasileira. Revista Científica Multidisciplinar Núcleo do Conhecimento. Ano 03, Ed. 03, Vol. 03, pp. 14-45, Março de 2018. ISSN: 2448-0959

ARSHED, N.; CARTER, S; MASON, C. The ineffectiveness of entrepreneurship policy: is policy formulation to blame? Small Business Economics, 43(3), p. 639-659, 2014

BAUMOL, W. J., 1993, 'Formal Entrepreneurship Theory in Economics: Existence and Bounds', Journal of Business Venturing 8, 197-210.

DOLABELA, Fernando. Pedagogia Empreendedora: ensino de empreendedorismo na educação básica. Disponível em: <http://fernandodolabela.wordpress.com/servicosoferecidos/pedagogiaempreendedora/>. Acesso em: $17 \mathrm{de} \mathrm{dez.} 2013$

DORNELAS, José Carlos Assis. Empreendedorismo: transformando ideias em negócios. 5. ed. Rio de Janeiro: Empreende / LTC, 2014.

LA ROVERE, R., SALLES, A.B.T., SANTOS, G e SANTOS, C. Desafios à formulação de políticas de apoio ao empreendedorismo no Brasil: o caso da Política Nacional de Empreendedorismo e Negócios (PNEN). In: Anais X EGEPE, SP: 4-6 Julho de 2018.

LAVIERI, Carlos. Educação... empreendedora?. In: LOPES, Rose Mary Almeida (org) Educação Empreendedora: conceitos, modelos, práticas. Rio de Janeiro: Elsevier; São Paulo: SEBRAE, capítulo 1, p. 01-16, 2010.

LOPES, Rose Mary Almeida (org). Educação Empreendedora: conceitos, modelos, práticas. Rio de Janeiro: Elsevier; São Paulo: SEBRAE, 2010.

MCCLOSKEY, Deirdre. Bourgeois Towns: How Capitalism Became Virtuous, 13001776. The Bourgeois Virtues, Vol. 2. Fonte: www.deirdremcclouskey.org

NORTH, Douglass C.. Institutions, Institutional Change and Economic Performance. UK: Cambridge University Press. 1990

University Press, 2005.

Understanding the Process of Economic Change. New Jersey: Princeton

OLSON, M. The Rise and Decline of Nations: Economic Growth, Stagflation and Social Rigidities, New Haven/London: Yale University Press: 1982.

PESSALI, H. Public Policy Design in Developing Societies - Beyond Transplantation. Journal of Developing Societies, Vol 27 n.1, p; 11-28, 2011.

PRAAG, C. M., 1996, Determinants of Successful Entrepreneurship, Amsterdam: Thesis Publishers. 
SALLES, A.B. T. Capitalismo no Brasil: o ambiente institucional para o empreendedorismo no início do Século XXI. Tese (Doutorado em Ciências Sociais)CPDA/UFRRJ, 2008.

SALLES, A. B. T.; LA ROVERE, R. L.; SANTOS, Guilherme de O. . Obstáculos às políticas de empreendedorismo no Brasil: Análise comparativa do período 2007-2015. Revista de Empreendedorismo, Inovação e Negócios, v. 3, p. 45-56, 2018

SEBRAE. Relatório Endeavor Final sobre Empreendorismo Nas Universidades Brasileiras 6/10/2016 disponível em: https://m.sebrae.com.br/Sebrae/Portal

SOUZA, Clair Gruber. Empreendedorismo e Capacitação Docente: uma sintonia possível. 179 folhas. Dissertação (mestrado em engenharia de produção) Universidade Federal de Santa Catarina - UFSC, Florianópolis, 2001.

SOUZA, Jessé (organizador). A invisibilidade da desigualdade brasileira. Belo Horizonte: Ed. UFMG, 2006.

VEIGA, Carolina. Espírito Santo Empreendedor. Vitória: SEBRAE, Findes, 2006.

WENNEKERS, S., THURIK, R. Linking Entrepreneurship and Economic Growth. In: Small Business Economics, v. 13: 27-55, 1999. 